\title{
Intra- and inter-exam reproducibility of left ventricular twist measurements using Fourier analysis of STimulated Echoes (FAST)
}

\author{
Meral Reyhan ${ }^{2,1^{*}}$, Hyun J Kim², Matthew S Brown ${ }^{1,2}$, Daniel Ennis ${ }^{1,2}$ \\ From 16th Annual SCMR Scientific Sessions \\ San Francisco, CA, USA. 31 January - 3 February 2013
}

\section{Background}

Assessing the reproducibility of new quantitative magnetic resonance imaging (MRI) biomarkers is an important part of validation [1-3]. Fourier Analysis of STimulated Echoes (FAST) [4] is a new MRI tissue tagging method that has recently been shown to compare favorably to conventional estimates of left ventricular (LV) twist from cardiac tagged images, but with significantly reduced user interaction time (less than $\sim 3$ minutes) and low intra- and interobserver variability. The purpose of this study was to assess the intra- and inter-exam reproducibility of LV twist using FAST.

\section{Methods}

After obtaining informed consent, healthy volunteers $(\mathrm{N}=10)$ were examined on Day- 1 and Day-8. On Day-1 MRI tagging was used to collect two measurements of LV twist for intra-exam comparisons. LV twist was measured again on Day-8 for inter-exam assessment. The following imaging parameters were used to acquire short-axis images at the base and apex: $280-330 \times 280-330 \mathrm{~mm}$ fieldof-view, 6mm slice thickness, 192x192 acquisition matrix, $395 \mathrm{~Hz} /$ pixel receiver bandwidth, TE/TR $=2.33-2.39 / 4.71$ $4.83 \mathrm{~ms}, 8 \mathrm{VPS}, 12^{\circ}$ imaging flip angle, $8 \mathrm{~mm}$ tag spacing, i-pat acceleration factor 2 with 24 central lines, and 14-27 cardiac phases. The breath hold duration was 15 heart beats (12.5 \pm 1.9 seconds) depending upon heart rate. LV short-axis tagged images were acquired on a 3T scanner in order to ensure detectability of tags during systole to mid-diastole. The collection order of horizontal and vertical tags at the apex and base of the LV was randomized for each exam. FAST was used to automatically estimate LV systolic and diastolic twist parameters subsequent to $\sim 3$ minutes of user interaction. Peak LV twist was reported as mean \pm SD. Reproducibility was assessed using the concordance correlation coefficient (CCC) and the repeatability coefficient $(\mathrm{RC}=95 \%$ - $\mathrm{CI}$ range).

\section{Results}

Mean peak twist measurements were $13.4 \pm 4.3^{\circ}$ (Day-1, Exam-1), 13.6 $\pm 3.7^{\circ}$ (Day-1, Exam-2), and 13.0 $\pm 2.7^{\circ}$ (Day-8). Bland-Altman analysis resulted in intra- and inter-exam bias and $95 \%-\mathrm{CI}$ of $-0.6^{\circ}\left[-1.0^{\circ}, 1.6^{\circ}\right]$ and $1.4^{\circ}\left[-1.0^{\circ}, 3.0^{\circ}\right]$, respectively. Paired t-tests showed no significant differences in peak LV twist for intra- and inter-exam values (all $\mathrm{p}>0.1$ ). The Bland-Altman RC for peak LV twist was $2.6^{\circ}$ and $4.0^{\circ}$ for intra- and inter-exam respectively. The CCC was 0.9 and 0.6 for peak LV twist for intra- and inter-exam respectively indicating excellent and moderate agreement respectively.

\section{Conclusions}

FAST is a semi-automated method that provides a quick and quantitative assessment of LV systolic and diastolic twist that demonstrates excellent intra-exam and moderate inter-exam reproducibility in preliminary studies. FAST estimates of LV twist may serve as a useful biomarker of LV dysfunction in longitudinal studies.

\section{Funding}

Funding from AHA and UCLA to MLR and NIH to DBE. 
Table 1

\begin{tabular}{llllll}
\hline & Mean Peak Twist & Bland-Altman Bias $(95 \%$ Cl) & RC & CCC & P-Value \\
\hline Intra-Exam & $13.4 \pm 4.3^{\circ}, 13.6 \pm 3.7^{\circ}$ & $-0.6^{\circ}\left[-1.0^{\circ}, 1.6^{\circ}\right]$ & $2.6^{\circ}$ & 0.9 & $P=0.9$ \\
\hline Inter-Exam & $13.4 \pm 4.3^{\circ}, 13.0 \pm 2.7^{\circ}$ & $1.4^{\circ}\left[-1.0^{\circ}, 3.0^{\circ}\right]$ & $4.0^{\circ}$ & 0.6 & $P=0.11$ \\
\hline
\end{tabular}

\section{Author details}

${ }^{1}$ Department of Radiological Sciences, University of California, Los Angeles,

CA, USA. ${ }^{2}$ Biomedical Physics Interdepartmental Program, University of

California, Los Angeles, CA, USA.

Published: 30 January 2013

\section{References}

1. Morton G, Schuster A, Jogiya R, Kutty S, Beerbaum P, Nagel E: Inter-study reproducibility of cardiovascular magnetic resonance myocardial feature tracking . Cardiovasc Magn Reson 14:43[http://www.jcmr-online.com/ content/14/1/43].

2. Greil GF, Desai MY, Fenchel M, Miller S, Pettigrew Rl, Sieverding L, Stuber M: Reproducibility of free-breathing cardiovascular magnetic resonance coronary angiography. Cardiovasc Magn Reson 2007, 9:49-56.

3. Varghese A, Crowe LA, Mohiaddin RH, Gathouse PD, Yang GZ, Firmin DN, Pennell DJ: Inter-study reproducibility of 3D volume selective fast spin echo sequence for quantifying carotid artery wall volume in asymptomatic subjects. . Atherosclerosis 2005, 183:361-366.

4. Reyhan M, Natsuaki Y, Ennis D: Fourier analysis of STimulated echoes (FAST) for the quantitative analysis of left ventricular twist . Magn Reson Imaging 2012, 35:587-593.

doi:10.1186/1532-429X-15-S1-E3

Cite this article as: Reyhan et al:: Intra- and inter-exam reproducibility of left ventricular twist measurements using Fourier analysis of STimulated Echoes (FAST). Journal of Cardiovascular Magnetic Resonance 201315 (Suppl 1):E3.

\section{Submit your next manuscript to BioMed Central and take full advantage of:}

- Convenient online submission

- Thorough peer review

- No space constraints or color figure charges

- Immediate publication on acceptance

- Inclusion in PubMed, CAS, Scopus and Google Scholar

- Research which is freely available for redistribution

Submit your manuscript at www.biomedcentral.com/submit
C Biomed Central 